\title{
PENERAPAN ALGORITMA DECISION TREE C4.5 BERBASIS SELEKSI ATRIBUT CHI SQUARED UNTUK KLASIFIKASI TINGKAT PENGETAHUAN IBU DALAM PEMBERIAN ASI EKSKLUSIF PADA BAYI
}

\author{
Erfan Karyadiputra' ${ }^{1)}$, Zaenuddin ${ }^{2)}$ \\ ${ }^{1}$ Fakultas Teknologi Informasi, Universitas Islam Kalimantan Muhammad Arsyad Al Banjari (Erfan \\ Karyadiputra) \\ email : erfantsy@gmail.com \\ ${ }^{1}$ Fakultas Teknologi Informasi, Universitas Islam Kalimantan Muhammad Arsyad Al Banjari (Zaenuddin) \\ email : zaenuddin.uniska@gmail.com
}

\begin{abstract}
Abstrak
Air susu ibu (ASI) merupakan salah satu anugerah ciptaan Allah Subhanahu Wa Ta'ala yang mengandung nutrisi alamiah terbaik bagi bayi dan mengandung kebutuhan energi serta zat yang dibutuhkan selama enam bulan pertama kehidupan bayi sehingga dapat melindunginya dari serangan berbagai penyakit. Dalam Al-Qur'an, Allah Subhanahu Wa Ta'ala juga telah menegaskan proses penyusuan seorang ibu kepada bayinya selama dua tahun penuh. Masa dua tahun ini merupakan rentang waktu tebaik ditinjau dari segala sisi kesehatan dan kejiwaan bagi bayi seperti yang tercantum dalam Al Qur'an Surah Al-Baqarah [2] ayat 233, Luqman [31] ayat 14, dan Al-Ahqaf [46] ayat 15. Penerapan teknik data mining seleksi atribut chi squared dapat meningkatkan akurasi menjadi 92,86\% dan meningkatkan nilai AUC menjadi 0,868 sehingga termasuk kedalam kategori good classification dengan mereduksi sejumlah atribut yang tidak relevan dan didapatkan atribut yang mempengaruhi tingkat pengetahuan ibu dalam pemberian ASI eksklusif pada bayi seperti atribut pendidikan, dukungan petugas kesehatan dan jumlah menyusui anak.
\end{abstract}

Keywords : Algoritma C4.5, Chi Squared, ASI, Data Mining, Klasifikasi, Seleksi Atribut

\section{PENDAHULUAN}

Air susu ibu (ASI) merupakan salah satu anugerah ciptaan Allah Subhanahu Wa Ta'ala yang berfungsi untuk memenuhi kebutuhan nutrisi pada bayi dan melindunginya dari serangan penyakit (Hasniati, Indah, Asrinawaty, \& Kasman, 2015). ASI juga mengandung nutrisi alamiah terbaik bagi bayi karena mengandung kebutuhan energi dan zat yang dibutuhkan selama enam bulan pertama kehidupan bayi (Arizki, Rahmawati, \& Mahdiyah, 2010). Dalam Al-Qur`an, Allah Subhanahu Wa Ta'ala juga telah menegaskan kelangsungan penyusuan ini selama dua tahun penuh (Asnawati, Bafadholl, \& Wahidin, 2019). Masa dua tahun ini merupakan rentang waktu emas ditinjau dari segala sisi kesehatan dan kejiwaan bagi bayi yang terdapat dalam $\mathrm{Al}$ Qur'an Surah Al-Baqarah [2] ayat 233, Luqman [31] ayat 14, dan Al-Ahqaf [46] ayat 15. Hal ini juga sejalan dengan pernyataan WHO dan UNICEF) untuk mengatur pola pemberian makan terbaik pada bayi dari sejak lahir sampai usia dua tahun untuk meningkatkan kualitas kesehatan bayi (Agustia, Machmud, \& Usman, 2019).

Menurut UNICEF dan WHO tentang laporan anak dunia tahun 2011 yaitu dari 136,7 juta bayi yang lahir di dunia, hanya sebesar $32,6 \%$ dari mereka menerima ASI secara eksklusif selama 6 bulan pertama (Hasniati et al., 2015). Hal tersebut sejalan dengan hasil Riset Kesehatan Dasar tahun 2010 di Indonesia yang menunjukkan pemberian ASI eksklusif 6 bulan pertama hanya $15,3 \%$, hal ini karena kesadaran masyarakat dalam mendorong peningkatan pemberian ASI masih relatif rendah (Kementerian Kesehatan Republik, 2019). Di Provinsi Kalimantan Selatan cakupan pemberian ASI eksklusif pada tahun 2011 sekitar 51,18\% yang menunjukan mengalami peningkatan dari tahun ke tahun, namun masih jauh dari target nasional yaitu $80 \%$ (Wijaya, 2018).

permasalahan pokok terkait masih rendahnya penggunaan ASI eksklusif di Indonesia adalah faktor kurangnya pengetahuan ibu hamil, sosial budaya, keluarga dan masyarakat akan pentingnya ASI ekslusif, serta 
instansi kesehatan yang belum sepenuhnya mendukung peningkatan pemberian ASI eksklusif (Kementerian Kesehatan Republik, 2019). Permasalahan ini diperparah dengan semakin gencarnya promosi susu formula dan kurangnya dukungan dari masyarakat, termasuk institusi yang memperkerjakan perempuan belum memberikan tempat bagi ibu menyusui di tempat kerja (Hartatik, 2009).

Beberapa penilitian terkait tentang klasifikasi tingkat pengetahuan ibu terhadapa ASI eksklusif diantaranya penelitian yang dilakukan oleh Yusfita Kumala Dewi yang mengklasifikasi tingkat pengetahuan ibu dalam pemberian ASI eksklusif menggunakan metode C4.5 dengan menghasilkan akurasi sebesar $55.24 \%$ dengan label 3 kategori dan 84,52 \% dengan label 2 kategori. Penelitian selanjutnya dilakukan oleh Yusuf Indra Wijaya yang melakukan klasifikasi tingkat pengetahuan ibu dalam pemberian ASI eksklusif menggunakan metode C4.5 berbasis PSO dan menghasilkan akurasi sebesar $92.77 \%$ dengan label 2 kategori (Wijaya, 2018). Pada penelitian ini akan dilakukan klasifikasi tingkat pengetahuan ibu dalam pemberian ASI eksklusif menggunakan metode decision tree berbasis seleksi atribut atau seleksi fitur untuk mereduksi fitur-fitur yang tidak relevan dan diketahui atribut yang berpengaruh (Anisah, H, \& Pujiastuti, n.d.).

\section{METODE PENELITIAN}

\section{a. Pengumpulan Data}

Tabel 1. Variabel Data ASI

\begin{tabular}{|c|c|c|c|}
\hline Variabel & Keterangan & & Kategori \\
\hline \multirow{2}{*}{ Y } & \multirow{2}{*}{$\begin{array}{c}\text { Tingkat } \\
\text { Pengetahuan }\end{array}$} & 1 & Kurang Baik \\
\hline & & 2 & Baik \\
\hline \multirow{3}{*}{$\mathrm{X} 1$} & \multirow{3}{*}{ Umur } & 1 & $<20$ Tahun \\
\hline & & 2 & 20 - 35 Tahun \\
\hline & & 3 & $>35$ \\
\hline \multirow{3}{*}{$\mathrm{X} 2$} & \multirow{3}{*}{ Pendidikan } & 1 & Tingkat Dasar \\
\hline & & 2 & Tingkat Menengah \\
\hline & & 3 & Tingkat Atas \\
\hline \multirow{2}{*}{$\mathrm{X} 3$} & \multirow{2}{*}{ Pekerjaan } & 1 & Tidak Bekerja \\
\hline & & 2 & Bekerja \\
\hline \multirow{2}{*}{$\mathrm{X} 4$} & \multirow{2}{*}{$\begin{array}{l}\text { Tempat } \\
\text { Bersalin }\end{array}$} & 1 & $\begin{array}{l}\text { Bukan Fasilitas } \\
\text { Kesehatan }\end{array}$ \\
\hline & & 2 & Fasilitas Kesehatan \\
\hline
\end{tabular}

\begin{tabular}{|c|c|c|c|}
\hline \multirow{3}{*}{$\mathrm{X} 5$} & \multirow{3}{*}{ Paritas } & 1 & Primipara \\
\hline & & 2 & Multipara \\
\hline & & 3 & Grandemultipara \\
\hline \multirow{6}{*}{$\mathrm{X} 6$} & \multirow{6}{*}{$\begin{array}{l}\text { Menyusui } \\
\text { Anak Ke - }\end{array}$} & 1 & Kesatu \\
\hline & & 2 & Kedua \\
\hline & & 3 & Ketiga \\
\hline & & 4 & Keempat \\
\hline & & 5 & Kelima \\
\hline & & 6 & keenam \\
\hline \multirow{4}{*}{$\mathrm{X} 7$} & \multirow{4}{*}{$\begin{array}{l}\text { Dukungan } \\
\text { Petugas } \\
\text { Kesehatan }\end{array}$} & 1 & Sangat Tidak Mendukung \\
\hline & & 2 & Tidak Mendukung \\
\hline & & 3 & Mendukung \\
\hline & & 4 & Sangat Mendukung \\
\hline \multirow{4}{*}{$\mathrm{X} 8$} & \multirow{4}{*}{$\begin{array}{l}\text { Promosi } \\
\text { Susu } \\
\text { Formula }\end{array}$} & 1 & Sangat Tidak Mendukung \\
\hline & & 2 & Tidak Mendukung \\
\hline & & 3 & Mendukung \\
\hline & & 4 & Sangat Mendukung \\
\hline \multirow{2}{*}{$\mathrm{X} 9$} & \multirow{2}{*}{$\begin{array}{l}\text { Dukungan } \\
\text { Orang Tua }\end{array}$} & 1 & Tidak Mendukung \\
\hline & & 2 & Mendukung \\
\hline \multirow{2}{*}{$\mathrm{X} 10$} & \multirow{2}{*}{$\begin{array}{l}\text { Dukungan } \\
\text { Suami }\end{array}$} & 1 & Tidak Mendukung \\
\hline & & 2 & Mendukung \\
\hline \multirow{2}{*}{$\mathrm{X} 11$} & \multirow{2}{*}{$\begin{array}{l}\text { Dukungan } \\
\text { Teman }\end{array}$} & 1 & Tidak Mendukung \\
\hline & & 2 & Mendukung \\
\hline \multirow{2}{*}{$\mathrm{X} 12$} & \multirow{2}{*}{$\begin{array}{l}\text { Dukungan } \\
\text { Tetangga }\end{array}$} & 1 & Tidak Mendukung \\
\hline & & 2 & Mendukung \\
\hline \multirow{4}{*}{$\mathrm{X} 13$} & \multirow{4}{*}{ Budaya } & 1 & Sangat Tidak Mendukung \\
\hline & & 2 & Tidak Mendukung \\
\hline & & 3 & Mendukung \\
\hline & & 4 & Sangat Mendukung \\
\hline
\end{tabular}

\section{b. Pengolahan Data Awal}

Pada tahap ini, data yang telah dikumpulkan melalui pengisian kuesioner kepada responden ibu menyusui yang berada di wilayah Puskesmas Tapin Utara. Kemudian diolah dengan melakukan pre-processing dengan mengidentifikasi beberapa atribut-atribut yang tidak relevan sehingga dapat diproses ketahapan selanjutnya dalam data mining.

\section{c. Eksperimen dan Pengujian Metode}

Pada tahap ini dilakukan eksperimen dalam mengimplementasikan pengujian algoritma C4.5 menggunakan rapidminer. 


\section{d. Eksperimen dan Pengujian Metode}

Tahap selanjutnya melakukan evaluasi dan validasi menggunakan $X$-Validation dan melakukan seleksi atribut chi squared.

\section{HASIL DAN PEMBAHASAN}

Sebelum melakukan eksperimen dan pengujian model, data-data yang dikumpulkan terlebih dahulu diolah agar dapat diproses dalam data mining.

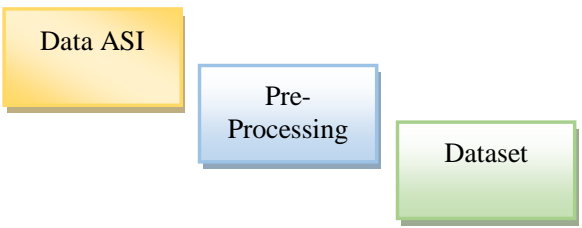

Gambar 1. Pre-Processing

Setelah data terkumpul, selanjutnya hitung Jumlah total data, kemudian hitung jumlah total data dengan variabel baik serta tidak baik seperti tabel berikut.

Tabel 2. Dataset

\begin{tabular}{|c|cc|c|c|}
\hline & $\begin{array}{c}\text { Jumlah } \\
\text { Atribut }\end{array}$ & $\begin{array}{c}\text { Jumlah } \\
\text { Data }\end{array}$ & Baik & $\begin{array}{c}\text { Kurang } \\
\text { Baik }\end{array}$ \\
\hline Total & 13 & 173 & 129 & 44 \\
\hline
\end{tabular}

Kemudian menghitung jumlah entrophy dari tiap-tiap jumlah dan atribut data.

$$
\begin{gathered}
\text { Entrophy }=\left(-\frac{\text { Jumlah Baik }}{\text { Jumlah Total }}\right) x \\
\log ^{2}\left(\left(\frac{\text { Jumlah Baik }}{\text { Jumlah Total }}\right)+\right. \\
\left(-\frac{\text { Jumlah Kurang Baik }}{\text { Jumlah Total }}\right) x \\
\log ^{2}\left(\left(\frac{\text { Jumlah Kurang Baik }}{\text { Jumlah Total }}\right)\right.
\end{gathered}
$$

Kemudian hitung gain dari setiap entrophy

\begin{tabular}{|c|c|c|c|c|c|c|}
\hline \multirow{4}{*}{$\begin{array}{l}\text { Pendidik } \\
\text { an }\end{array}$} & & & & & & $\begin{array}{c}0.0161122 \\
19\end{array}$ \\
\hline & $\begin{array}{c}\text { Tingkat } \\
\text { Dasar }\end{array}$ & 40 & 26 & 14 & $\begin{array}{c}0.9340680 \\
55\end{array}$ & \\
\hline & $\begin{array}{c}\text { Tingkat } \\
\text { Menengah }\end{array}$ & 100 & 75 & 25 & $\begin{array}{c}0.8112781 \\
24\end{array}$ & \\
\hline & Tingkat Atas & 33 & 28 & 5 & $\begin{array}{c}0.6136190 \\
2\end{array}$ & \\
\hline \multirow{3}{*}{$\begin{array}{c}\text { Pekerjaa } \\
\text { n }\end{array}$} & & & & & & $\begin{array}{c}0.0001315 \\
61\end{array}$ \\
\hline & Bekerja & 45 & 34 & 11 & $\begin{array}{c}0.8023534 \\
43\end{array}$ & \\
\hline & $\begin{array}{c}\text { Tidak } \\
\text { Bekerja } \\
\end{array}$ & 128 & 95 & 33 & $\begin{array}{c}0.8234274 \\
32\end{array}$ & \\
\hline \multirow{3}{*}{$\begin{array}{l}\text { Tempat } \\
\text { Bersalin }\end{array}$} & & & & & & $\begin{array}{c}0.0025269 \\
44\end{array}$ \\
\hline & $\begin{array}{c}\text { Fasilitas } \\
\text { Kesehatan }\end{array}$ & 103 & 79 & 24 & $\begin{array}{c}0.7832211 \\
18 \\
\end{array}$ & \\
\hline & $\begin{array}{c}\text { Bukan } \\
\text { Fasilitas } \\
\text { Kesehatan }\end{array}$ & 70 & 50 & 20 & $\begin{array}{c}0.8631205 \\
69\end{array}$ & \\
\hline \multirow{4}{*}{ Paritas } & & & & & & $\begin{array}{c}0.0089615 \\
28 \\
\end{array}$ \\
\hline & Primipara & 48 & 34 & 14 & $\begin{array}{c}0.8708644 \\
69 \\
\end{array}$ & \\
\hline & Multipara & 122 & 92 & 30 & $\begin{array}{c}0.8047175 \\
19 \\
\end{array}$ & \\
\hline & $\begin{array}{c}\text { Grandemulti } \\
\text { para }\end{array}$ & 3 & 3 & 0 & 0 & \\
\hline \multirow{7}{*}{$\begin{array}{l}\text { Menyus } \\
\text { ui Anak }\end{array}$} & & & & & & $\begin{array}{c}0.0169847 \\
14 \\
\end{array}$ \\
\hline & Kesatu & 49 & 35 & 14 & $\begin{array}{c}0.8631205 \\
69 \\
\end{array}$ & \\
\hline & Kedua & 78 & 61 & 17 & $\begin{array}{c}0.7564041 \\
95\end{array}$ & \\
\hline & Ketiga & 31 & 23 & 8 & $\begin{array}{c}0.8238116 \\
33 \\
\end{array}$ & \\
\hline & Keempat & 12 & 7 & 5 & $\begin{array}{c}0.9798687 \\
57 \\
\end{array}$ & \\
\hline & Kelima & 2 & 2 & 0 & 0 & \\
\hline & Keenam & 1 & 1 & 0 & 0 & \\
\hline \multirow{4}{*}{$\begin{array}{c}\text { Dukunga } \\
n \\
\text { Petugas }\end{array}$} & & & & & & $\begin{array}{c}0.0222522 \\
06\end{array}$ \\
\hline & $\begin{array}{l}\text { Sangat Tidak } \\
\text { Mendukung }\end{array}$ & 2 & 1 & 1 & 1 & \\
\hline & Mendukung & 56 & 36 & 20 & $\begin{array}{c}0.9402859 \\
59\end{array}$ & \\
\hline & $\begin{array}{c}\text { Sangat } \\
\text { Mendukung }\end{array}$ & 115 & 92 & 23 & $\begin{array}{c}0.7219280 \\
95\end{array}$ & \\
\hline \multirow{3}{*}{$\begin{array}{l}\text { Dukunga } \\
\text { n Suami }\end{array}$} & & & & & & $\begin{array}{c}0.0003516 \\
11\end{array}$ \\
\hline & $\begin{array}{c}\text { Tidak } \\
\text { Mendukung }\end{array}$ & 5 & 4 & 1 & $\begin{array}{c}0.7219280 \\
95 \\
\end{array}$ & \\
\hline & Mendukung & 168 & 125 & 43 & $\begin{array}{c}0.8205768 \\
27 \\
\end{array}$ & \\
\hline \multirow{3}{*}{$\begin{array}{c}\text { Dukunga } \\
\text { n Orang } \\
\text { Tua }\end{array}$} & & & & & & $\begin{array}{c}0.0021475 \\
22 \\
\end{array}$ \\
\hline & $\begin{array}{c}\text { Tidak } \\
\text { Mendukung }\end{array}$ & 44 & 31 & 13 & $\begin{array}{c}0.8756633 \\
92\end{array}$ & \\
\hline & Mendukung & 129 & 98 & 31 & $\begin{array}{c}0.7955555 \\
47\end{array}$ & \\
\hline \multirow{3}{*}{$\begin{array}{l}\text { Dukunga } \\
\mathrm{n} \text { Teman }\end{array}$} & & & & & & $\begin{array}{c}0.0013288 \\
17\end{array}$ \\
\hline & $\begin{array}{c}\text { Tidak } \\
\text { Mendukung }\end{array}$ & 120 & 88 & 32 & $\begin{array}{c}0.8366407 \\
42\end{array}$ & \\
\hline & Mendukung & 53 & 41 & 12 & $\begin{array}{c}0.7717094 \\
7 \\
\end{array}$ & \\
\hline \multirow{3}{*}{$\begin{array}{c}\text { Dukunga } \\
\text { n } \\
\text { Tetangg } \\
\text { a }\end{array}$} & & & & & & $\begin{array}{c}0.0000013 \\
73 \\
\end{array}$ \\
\hline & $\begin{array}{c}\text { Tidak } \\
\text { Mendukung }\end{array}$ & 126 & 94 & 32 & $\begin{array}{c}0.8175072 \\
88\end{array}$ & \\
\hline & Mendukung & 47 & 35 & 12 & $\begin{array}{c}0.8196004 \\
35\end{array}$ & \\
\hline \multirow{5}{*}{$\begin{array}{l}\text { Promosi } \\
\text { Susu }\end{array}$} & & & & & & $\begin{array}{c}0.0091737 \\
09\end{array}$ \\
\hline & $\begin{array}{l}\text { Sangat Tidak } \\
\text { Mendukung }\end{array}$ & 11 & 10 & 1 & $\begin{array}{c}0.4394969 \\
87 \\
\end{array}$ & \\
\hline & $\begin{array}{c}\text { Tidak } \\
\text { Mendukung }\end{array}$ & 56 & 42 & 14 & $\begin{array}{c}0.8112781 \\
24\end{array}$ & \\
\hline & Mendukung & 93 & 68 & 25 & $\begin{array}{c}0.8397622 \\
74\end{array}$ & \\
\hline & $\begin{array}{c}\text { Sangat } \\
\text { Mendukung }\end{array}$ & 13 & 9 & 4 & $\begin{array}{c}0.8904916 \\
4\end{array}$ & \\
\hline
\end{tabular}
tersebut seperti tabel berikut

Tabel 3. Perhitungan Entrophy \& Gain

\begin{tabular}{|c|c|c|c|c|c|c|}
\hline \multirow{4}{*}{ Total } & & $\begin{array}{c}\text { Juml } \\
\text { ah }\end{array}$ & Baik & $\begin{array}{c}\text { Kura } \\
\text { ng } \\
\text { Baik }\end{array}$ & Entrophy & Gain \\
\cline { 3 - 7 } & 173 & 129 & 44 & $\begin{array}{c}0.8180773 \\
19\end{array}$ & \\
\hline \multirow{4}{*}{ Umur } & $<20$ Tahun & 6 & 5 & 1 & $\begin{array}{c}0.6500224 \\
22\end{array}$ & $\begin{array}{c}0.0016118 \\
16\end{array}$ \\
\cline { 2 - 7 } & 20-35 Tahun & 133 & 98 & 35 & $\begin{array}{c}0.8314743 \\
88\end{array}$ & \\
\cline { 2 - 7 } & $>35$ Tahun & 34 & 26 & 8 & $\begin{array}{c}0.7871265 \\
86\end{array}$ & \\
\cline { 2 - 7 } & & & & & \multicolumn{4}{|c}{} \\
\hline
\end{tabular}




\begin{tabular}{|c|c|c|c|c|c|c|}
\hline \multirow{5}{*}{ Budaya } & & & & & $\begin{array}{c}0.0053454 \\
64\end{array}$ \\
\cline { 2 - 7 } & $\begin{array}{c}\text { Sangat Tidak } \\
\text { Mendukung }\end{array}$ & 1 & 1 & 0 & 0 & \\
\cline { 2 - 7 } & $\begin{array}{c}\text { Tidak } \\
\text { Mendukung }\end{array}$ & 24 & 18 & 6 & $\begin{array}{c}0.8112781 \\
24\end{array}$ & \\
\cline { 2 - 7 } & Mendukung & 94 & 72 & 22 & $\begin{array}{c}0.7849920 \\
89\end{array}$ & \\
\hline $\begin{array}{c}\text { Sangat } \\
\text { Mendukung }\end{array}$ & 54 & 38 & 16 & $\begin{array}{c}0.8767162 \\
89\end{array}$ & \\
\hline
\end{tabular}

Selanjutnya melakukan implementasi pengujian algoritma C4.5 menggunakan rapidminer.

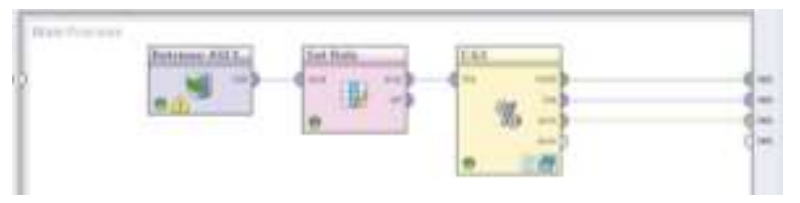

Gambar 2. Implementasi C4.5

Selanjutnya evaluasi dan validasi melalui pengujian confusion matrix dan kurva ROC sehingga diketahui akurasi dan modelnya.

\begin{tabular}{|c|c|c|c|}
\hline & nebass & hakiagybak & dass peocsitr \\
\hline pet bat: & 10 & 3 & $\mathrm{Ka4}$ \\
\hline pat Virangai & 8 & 16 & Et67. \\
\hline dass tecal & 99045 & sthe & \\
\hline
\end{tabular}

Gambar 3. Hasil Akurasi C.45

Dari hasil pengujian 10-fold crossvalidation, didapatkan akurasi sebesar $87,89 \%$ dengan nilai AUC sebesar 0,679.

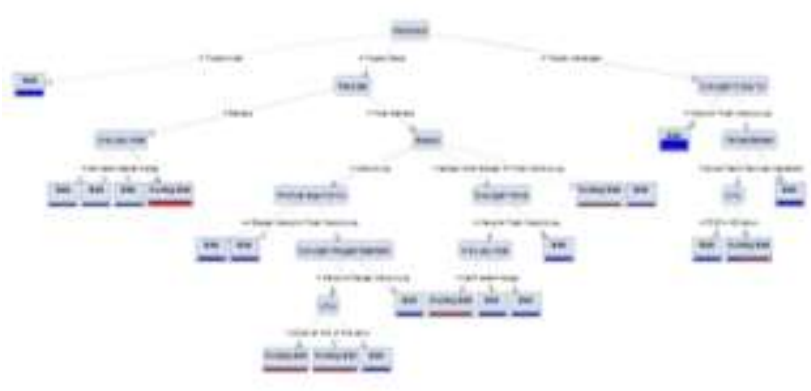

Gambar 4. Model Pohon Keputusan

Selanjutnya melakukan seleksi atribut menggunakan chi squared untuk meningkatkan akurasi dan mengetahui atribut yang berpengaruh.

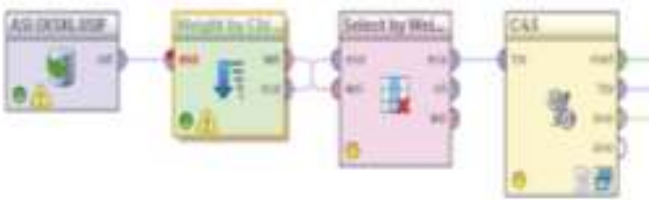

Gambar 5. Seleksi Atribut Chi Squared
Dari hasil percobaan seleksi atribut chi squared dengan mengganti nilai weight relation top $k$ maka didapatkan seleksi atribut dengan nilai top $k=3$ memiliki akurasi terbaik sebesar 92,90\% dengan nilai AUC sebesar 0,868.

\begin{tabular}{|c|c|c|c|}
\hline \multicolumn{4}{|c|}{ 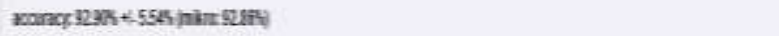 } \\
\hline & helat & taakiargBa: & destpecisict \\
\hline vet Pak & $\pi 4$ & I & 2025 \\
\hline reckrangal & 1 & 15 & sata \\
\hline dassieal & 90154 & $54 \mathrm{~m}$ & \\
\hline
\end{tabular}

Gambar 6. Hasil Akurasi Chi Squared

Dari hasil seleksi atribut didapatkan atribut yang berpengaruh dalam klasifikasi tingkat pengetahuan ibu dalam pemberian ASI eksklusif yaitu atribut pendidikan, dukungan petugas kesehatan dan jumlah menyusui anak seperti yang tergambarkan pada pohon keputusan berikut

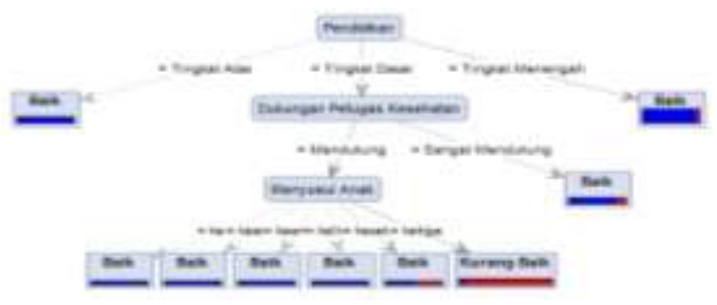

Gambar 7. Model Pohon Keputusan

\section{KESIMPULAN}

Dari hasil penelitian yang dilakukan dari tahap awal pengujian hingga akhir pengujian, maka dapat disimpulkan bahwa penerapan teknik seleksi atribut chi squared dapat meningkatkan akurasi dan kehandalan klasifikasi algoritma C4.5 dengan mereduksi sejumlah atribut yang tidak relevan sehingga didapatkan atribut yang mempengaruhi tingkat pengetahuan $\mathrm{ibu}$ dalam pemberian ASI eksklusif pada bayi.

\section{REFERENSI}

Agustia, N., Machmud, R., \& Usman, E.

(2019). FAKTOR YANG

BERHUBUNGAN DENGAN

PEMBERIAN ASI EKSKLUSIF PADA IBU BEKERJA DI KABUPATEN OGAN KOMERING ULU, 8(3), 573-582.

Anisah, S., H, A. S., \& Pujiastuti, A. (n.d.). KLASIFIKASI TEKS 
MENGGUNAKAN CHI SQUARE FEATURE SELECTION UNTUK MENENTUKAN KOMIK BERDASARKAN PERIODE, MATERI DAN FISIKDENGAN ALGORITMA NAIVE BAYES, 59-66.

Arizki, W., Rahmawati, D., \& Mahdiyah, D. (2010). HUBUNGAN PENGETAHUAN IBU TENTANG ASI EKSKLUSIF TERHADAP PEMBERIAN ASI PADA BAYI 0-6 BULAN DI PUSKESMAS S.PARMAN BANJARMASIN, 39-48.

Asnawati, Bafadholl, I., \& Wahidin, A. (2019). PEMBERIAN ASI PADA ANAK DALAM PERSPEKTIF AL-QUR `AN, (1), 85-98.

https://doi.org/10.30868/at.v4i01.429

Hartatik, T. (2009). HUBUNGAN PENGETAHUAN DAN SIKAP IBU DENGAN PEMBERIAN ASI EKSKLUSIF DI KELURAHAN GUNUNGPATI KECAMATAN GUNUNGPATI KOTA SEMARANG TAHUN 2009.

Hasniati, Y., Indah, M. F., Asrinawaty, \& Kasman. (2015). DETERMINAN
PEMBERIAN ASI EKSKLUSIF DI KABUPATEN BARITO KUALA KALIMANTAN SELATAN, 39-43.

Karyadiputra, E., \& Hijriana, N. (2019). PENERAPAN ALGORITMA DECISION TREE C4. 5 UNTUK KLASIFIKASI PENENTUAN DAFTAR PRIORITAS PENGEMBANGAN JEMBATAN. Technologia: Jurnal Ilmiah, 10(1), 43-46.

Karyadiputra, E., \& Hijriana, N. (2018). ANALISIS PENERAPAN ALGORITMA NAIVE BAYES UNTUK KLASIFIKASI PRIORITAS PENGEMBANGAN JALAN DI PROVINSI KALIMANTAN SELATAN. Technologia: Jurnal Ilmiah, 9(2), 105-108.

Kementerian Kesehatan Republik. (2019). BANYAK SEKALI MANFAAT ASI BAGI BAYI DAN IBU, 1-2.

Wijaya, Y. I. (2018). KLASIFIKASI TINGKAT PENGETAHUAN IBU DALAM PEMBERIAN ASI EKSKLUSIF MENGGUNAKAN ALGORITMA DECISION TREE C4.5 BERBASIS PSO, 9(2), 120-124. 